\title{
Seeing lockdown through the eyes of children from around the world: Reflecting on a children's artwork project
}

Mandie Jane Foster ${ }^{1,2,14}$, PhD, RN, Senior Lecturer \& Research Scholar, Nursing

Mohammad Al-Motlaq ${ }^{3}$, PhD RN. Associate Professor Maternal Child \& Family Health

Bernie Carter ${ }^{4,5,1}$, PhD, RGN, RSCN, Professor of Children's Nursing

Sarah Neill6,7, PhD, RGN, RSCN, Professor in Nursing

Therese O'Sullivan ${ }^{2}$, PhD, Associate Professor, Nutrition Research

Angela A Quaye ${ }^{8}$, MSc, PhD Candidate, Child \& Family Health

Maureen Majamanda ${ }^{9}$, MSc, RN, Senior Lecturer, Child Health

Khatijah Abdullah ${ }^{10}$, DClinP, RM, RN, Professor of Nursing

Inger K Hallström ${ }^{8}$, PhD, RSCN, RN, Professor of Paediatric Nursing

Christine English ${ }^{11}$, PhD, RGN, RSCN, Associate Lecturer \& Chair Clinical Governance

Amanda Vickers ${ }^{12}$, GradDipNursEd, BM, BN, RM, RN, Lecturer in Nursing

Imelda Coyne ${ }^{13}$, PhD, RGN, RSCN, Professor in Children's Nursing

Esther Adama ${ }^{2}, \mathrm{PhD}, \mathrm{RN}$, Lecturer in Nursing

Evalotte Morelius ${ }^{2}$, PhD, RN, Professor of Nursing

\section{Citation}

Foster, M. J.; Al-Motlaq, M., Carter, B., Neill, S., O'Sullivan, T., Quaye, A. A., Majamanda, M., Abdullah, K., Hallström, I. K., English, C., Vickers, A., Coyne, I., Adama, E., \& Morelius, E. (2021). Seeing lockdown through the eyes of children from around the world: Reflecting on a children's artwork project. Nursing Praxis in Aotearoa New Zealand, 37(3), 104-115. https://doi.org.10.36951/27034542.2021.039

${ }^{1}$ Auckland University of Technology, Auckland, New Zealand; ${ }^{2}$ Edith Cowan University, Perth, Australia; ${ }^{3}$ The Hashemite University, Zarqa, Jordan; ${ }^{4}$ Edge Hill University, Ormskirk, UK; ${ }^{5}$ University of Tasmania, Australia; ${ }^{6}$ University of Plymouth, Devon, UK; ${ }^{7}$ Charles Sturt University, Bathurst, Australia; ${ }^{8}$ Lund University, Sweden; ${ }^{9}$ Kamuz University of Health Sciences, Malawi; ${ }^{10}$ Sunway University, Sunway, Malaysia; ${ }^{11}$ Northumbria University/St Oswald's Hospice Newcastle, UK; ${ }^{12}$ Australian Catholic University, Canberra, Australia; ${ }^{13}$ Trinity College Dublin, Ireland.

${ }^{14}$ Corresponding Author: Mandie Foster mandie.foster@aut.ac.nz

\begin{abstract}
The COVID-19 pandemic created new challenges for children including access to education and limiting social and emotional connections to extended family, friends, and the community. Globally, opportunities for sharing children's self-reported experiences during lockdown were limited. The primary aim of this project was to create an art-eBook that reflects children's experiences of life during the COVID-19 pandemic that could be shared with other children around the world. Secondly, we wanted to reflect on the consultation undertaken within the International Network of Child and Family Centered Care (INCFCC) using Gibbs (1988) reflective cycle framework. Children from around the world were invited to submit a piece of artwork that reflected their experience during the COVID-19 pandemic via a Qualtrics-survey in May 2020. The children's artwork and written pieces were transcribed verbatim into an eBook and the artwork was further placed into groups based on similarity of meaning. Fifty-five children from 17 countries submitted an artwork piece. Four groups were evident within the children's artwork including infection control measures, positive experiences and emotions (connection to family, fun activities), negative experiences and emotions (social impact, emotional impact), and uniting children globally. The eBook illustrates how children of all ages can provide meaningful insightful commentary and valuable information on their experiences during an unprecedented pandemic.
\end{abstract}

Keywords: arts-based approach, child and family centred care; children's experiences; COVID-19, eBook, Gibbs reflective cycle 


\section{Introduction}

The Director General of the World Health Organization (WHO), in his media briefing on COVID19 on March 11, 2020, announced that the COVID-19 pandemic had affected more than 118,000 cases in 114 countries, and 4,291 people had lost their lives (World Health Organisation, 2020b). Sixty percent of all children worldwide were living in countries that had a full or partial lockdown in place (United Nations, 2020a). The COVID-19 pandemic brought with it significant changes and challenges not least for children and young people; these changes have been influenced by the enforced lockdown restrictions imposed by most countries, states and/or territories (Cooper, 2020; Royal College of Paediatrics and Child Health, 2021). Restrictions include the closure of schools; variable access to alternative online learning; inability for children to socialize; limited opportunities to develop important social and behavioural skills; the loss of loved ones; and adverse news about the virus (de Figueiredo et al., 2021; Lee, 2020; Nearchou et al., 2020). Children have been variably impacted through lack of resources, support or skills to invest in digital learning in schools; lack of access to digital devices; no or variable internet access; and limited parental support (UNICEF, 2020).

It has been reported that the first lockdown had a significant impact on the social and emotional development of young children (3-6 years), older children (7-9 years), and adolescents (10-18 years) (Nearchou et al., 2020). The effect on young children (3-6 years) included signs of insecurity, fear of family members being infected, feelings of isolation, disturbed sleep, nightmares, poor appetite, and separation anxiety from parents who were required to be quarantined (Jiao et al., 2020; Royal College of Paediatrics and Child Health, 2021). For older children and adolescents (7-18 years) the effects included feelings of uncertainty about cancelled exams or academic events, depression, inattention, suicidal ideation and self-harm, with increased use of the internet and social media (Jiao et al., 2020; Lee, 2020; UNICEF, 2020; Viner et al., 2020). The constant messages about the use of handwashing, sanitisers, mask use, glove wearing, social distancing, escalating numbers of COVID-19 cases, social media, and fear of food and medication insufficiency have been shown globally to heighten child and family distress (AlMotlaq, 2021; Cooper, 2020; Liu et al., 2020; United Nations, 2020b). Children with disabilities, mental health disorders, comorbidities, and under privileged populations have been shown to be further at risk of adverse health outcomes and abuse occurring within the family during the COVID-19 lockdown (Cooper, 2020; UNICEF, 2020a). UNICEF (2020a) reports that the resources available during the COVID-19 pandemic have not been distributed equally for children in the poorest countries and those in already disadvantaged or vulnerable situations.

Parental and other guidance and advocacy for children's best interests during the COVID-19 pandemic needs to be actioned in a way that takes account of their competency, capacity, and developmental age; this can be achieved by legalisation and action by international organisations, and advisory bodies (Singh et al., 2020; Tang et al., 2021). It is vital to plan child focused ageappropriate initiatives and programmes to enhance children's and adolescents' ability to access videos, booklets and explanations on COVID-19 including online counselling services during and after lockdowns (Dewa et al., 2020; Singh et al., 2020; World Health Organisation, 2020a).

The International Network for Child and Family Centered Care (INCFCC, 2020a) is a growing global collaboration of experts in child and family centered care. Members of the network communicate and collaborate in research, practice development and education to identify good practice and develop the evidence base to influence positive change at local, national, and international levels (Al-Motlaq et al., 2018; Al-Motlaq \& Shields, 2017; Foster \& Shields, 2019; Quaye et al., 2019; Smith et al., 2017). The collaborative network works to achieve its vision through considering the specific challenges of different cultures and care settings and by ensuring that children and their families are central to the network's collaborative enterprise (Al-Motlaq et al., 2021; Foster et al., 2018).

During the first COVID-19 pandemic lockdown, a team of twenty-one members of the INCFCC expressed an interest in children's experiences of life during lockdown. Children can often find expressing their ideas and feelings is easier if they can use creative methods such as art, poems, songs or photos (Foster \& Whitehead, 2018; Rogers, 2018). The team wanted to create an eBook of artwork that reflected children's experiences during the COVID-19 pandemic that could be shared with other children 
around the world, to help acknowledge their feelings during this difficult time.

This article uses the Gibbs (1988) reflective cycle to explore how this arts-based project contributed to the appreciation and deeper understanding of children's experiences of the pandemic. Reflection is important:

\section{It is not sufficient simply to have an experience in order to learn. Without reflecting upon this experience, it may quickly be forgotten, or its learning potential lost. It is from the feelings and thoughts emerging from this reflection that generalisations or concepts can be generated, and it is generalisations that allow new situations to be tackled effectively. (Gibbs, 1988, p. 14)}

Within this article we used the six stages of the reflective cycle (Gibbs, 1988) to report on our experience of undertaking this eBook project. It shows how this experience has enhanced our ongoing learning. The six stages were: description what happened; feelings - what you were thinking and feeling about the experience; evaluation - what was good or bad about the experience; analysis - what sense you can make of the situation; conclusion what else could you have done; and action plan - if it arose again, what would you do.

\section{Stage 1: Description of the project}

The eBook project was not a research study but rather a unique examination that adopted a consultation approach to find out about children's experiences and ideas of the lockdown. To ensure ethical compliance and outcomes of any future reporting of the experience, the team provided sufficient information about the project to children to be able to make an informed decision prior to providing assent or consent both for their participation in the project and use of their artwork. A key reason for not undertaking this as a research study was that we wished to gain insight into children's contemporaneous experiences during lockdown and we wished to undertake this globally. Given the number of countries involved it would have been impossible to secure ethical approval in all these countries within the time frame, consequently we chose an ethically conducted consultation approach. Twenty-one of the 67 INCFCC members worked on the eBook art project during 2020.
The eBook project involved inviting children, grandchildren, or close kin and friends (up to 18 years of age) of members of the INCFCC to participate via a Qualtrics survey between 1 and 31 May 2020. Children were asked, with parental assistance as needed, to submit an image of a piece of artwork (such as drawings, poetry, stories, letters, collage, LEGO, and other creative play resources) that reflected something about their experience during the COVID-19 pandemic. They were also asked to explain why they decided to share this piece of artwork, provide details about their artwork, their age, the country they live in and their given name or the pseudonym that they would like to accompany their artwork. Comments were either written by the child or by their parent. Children provided voluntary informed assent and parents confirmed their consent by submitting their art piece through the Qualtrics portal.

At the time of artwork entry, parents were asked about the level of COVID-19 restrictions experienced by their child; the restriction options were 'none' (no change to normal living routine); 'minimal' (still attending school, but not allowed to play with friends after school); some (still attending school but not allowed to play with friends after school and needed to stay 1.5-2 metres apart); 'moderate' (home schooling, able to go to parks); or 'severe' (not allowed to leave the family home).

Children's contributions (words, poetry, stories, photographs, and drawings) were collated into an eBook and structured so that the children's contributions were presented in sections for the different countries. The level of lockdown restriction was also included as part of the child's page. Responses submitted in a language other than English, included a translation into English, beneath the submitted image. Translation was carried out by multilingual members of the INCFCC who were fluent in the identified language. Languages translated to English included Arabic, Swedish, and Turkish. The team did not analyse the data but instead used a descriptive approach to place the children's art pieces into groups based on similarity. This included four steps: (1) each child's art submission was presented and discussed individually amongst the members during several online recorded meetings; (2) the art pieces were then transcribed verbatim into an eBook; (3) the descriptions that accompanied the art pieces were placed into groups based on 
similarity; and (4) the eBook and groups were discussed amongst the members until a consensus was reached. To ensure ethical integrity of outcomes, the team gained children's assent and parental consent from children both for participation, use of their artwork and for their given name and age to be used in the eBook, if they so wished. All the children wanted their name to be linked to their artwork.

\section{Findings}

A total of fifty-five children (aged 4-14 years) across 17 countries participated (Figure 1). Forty-two children were in a severe or moderate level of restriction (Figure 2). The eBook is available to download free of charge via the INCFCC website (2020b) and we distributed it directly to all the children and families who participated.

Four groups were evident within the children's art submissions. These were infection control measures, positive experiences and emotions (connection to family, fun activities), negative experiences and emotions (social impact, emotional impact), and recognition of the wider impact of COVID-19.

Figure 1: Countries of residence of participating children

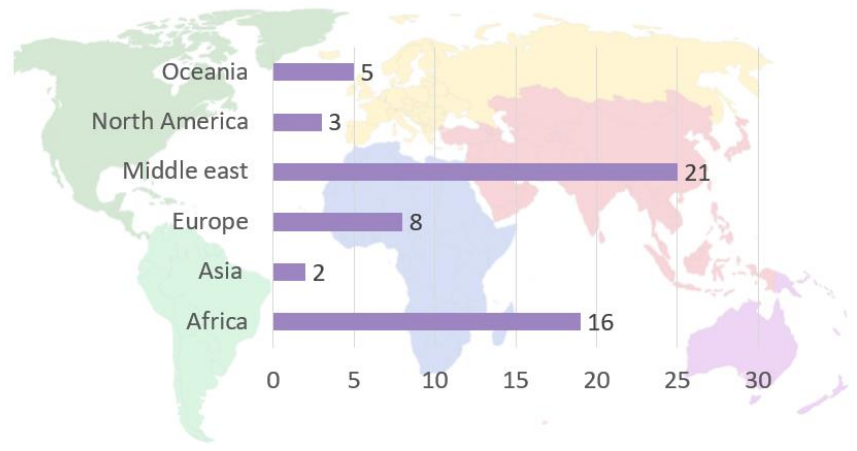

Figure 2: Level of restrictions experienced by participating children

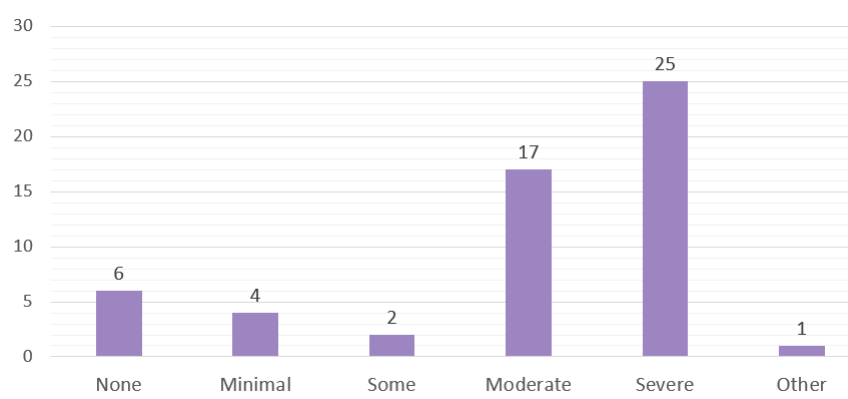

Children engaged with the project using different art forms; pictures $(n=42)$, stories $(n=8)$, photos $(n=4)$, poems $(n=3)$, Lego $(n=3)$ and computer-generated pictures $(n=3)$ representing 63 art pieces. Five children submitted more than one picture. Seven of the children's art pieces have been selected for inclusion in this paper as they reflect various aspects of their COVID-19 lockdown that support the four groups (Figures 3-10).

\section{Infection Control Measures}

Over a third of children $(n=23)$, including some as young as four years of age, used the same basic image of the coronavirus showing the proteins on the outer shell of the virus, illustrating the power of images circulated in global media as shown in the artwork (Figures 3 and 4).

Figure 3: Kekey 10 years old from Indonesia

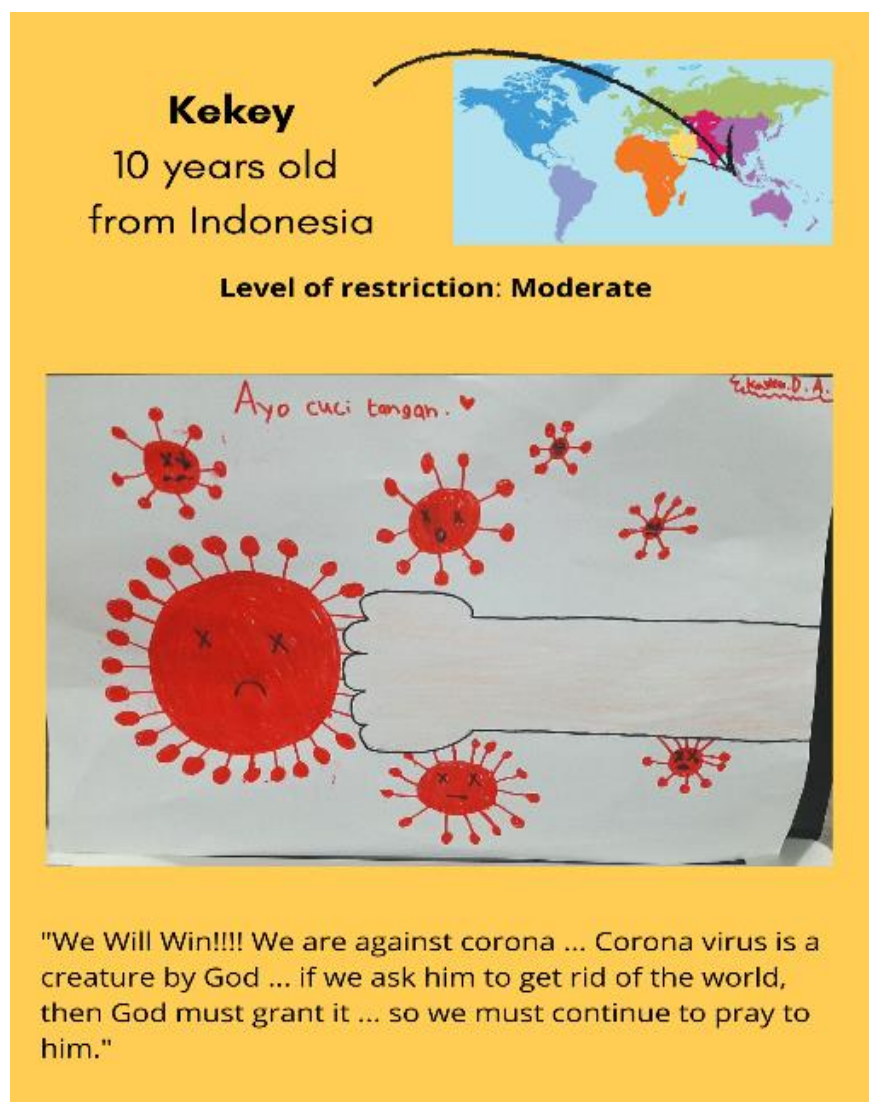

A common area, evident in the majority of the children's artwork, concerning infection control was preventative strategies to limit transmission of the virus. This included washing hands properly " $A s$ we begin to go out to play as children, the more we wash our hands with soap and water the happier (smiling) our hands will be" (Olachi, 11yrs, Nigeria). Other children noted this also involved "not touching one's eyes, nose or mouth" (Hebah, 14yrs, Jordan); sneezing or coughing into one's elbow "Any time I sneeze or cough, I have to do it inside my elbows" (Natasha, 10yrs, United Kingdom). 
Figure 4: Apek, 9 years old from Turkey

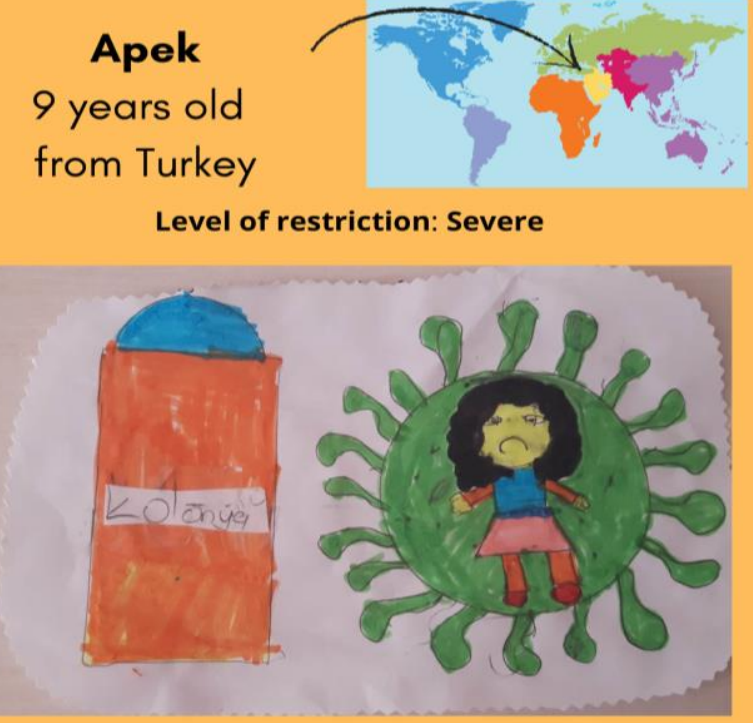

"I wanted to show how it is difficult to stay at home. The meaning of the word in the picture: 'kolonya' means a kind of solution which contains alcohol. In my picture, I wanted to show that I got bored too much. This picture It shows the corona virus itself and tells to protect ourselves. Isolation protects us from corona virus. It made us to be more careful about hygiene with mask and alcohol. We do not get ill by using social through isolation. But I got so bored of being at home. I got so bored of hearing the coronavirus everytime. I feel lonely. I missed my friends. I want this period to get over soon. I am very bored."

Other methods noted included social distancing: "Observe social distance since prevention is better than cure" (Favour, 10yrs, Malawi); "avoiding crowds" (Lady T, 7yrs, Zambia); "Isolation protects us from corona virus" (Apek, 9yrs, Turkey); and "staying at home" (Momo, 6yrs, Zambia). Other measures children talked about were using "mask on our mouths" (Luyando, 13yrs, Zambia) and using disinfectant "We use Clolex [Clorex: disinfectant] to stop Colona [corona virus]" (Yara, 4yrs, Saudi Arabia). One child talked about listening to adults: "The ears are representing how important it is to listen" (Momo, 6yrs, Zambia). Children as young as 4 years old seemed very intuitive, insightful and had a good understanding for their age on what was important and how to keep safe.

\section{Positive experiences and emotions}

Positive experiences included 'connection to family' and 'fun activities' experienced during the COVID-19 lockdown.

\section{Positive experiences and emotions: Connection to family}

Connection to family included being able to stay at home; normal household rules or schedules were
Figure 5: Natasha 10 years old from UK

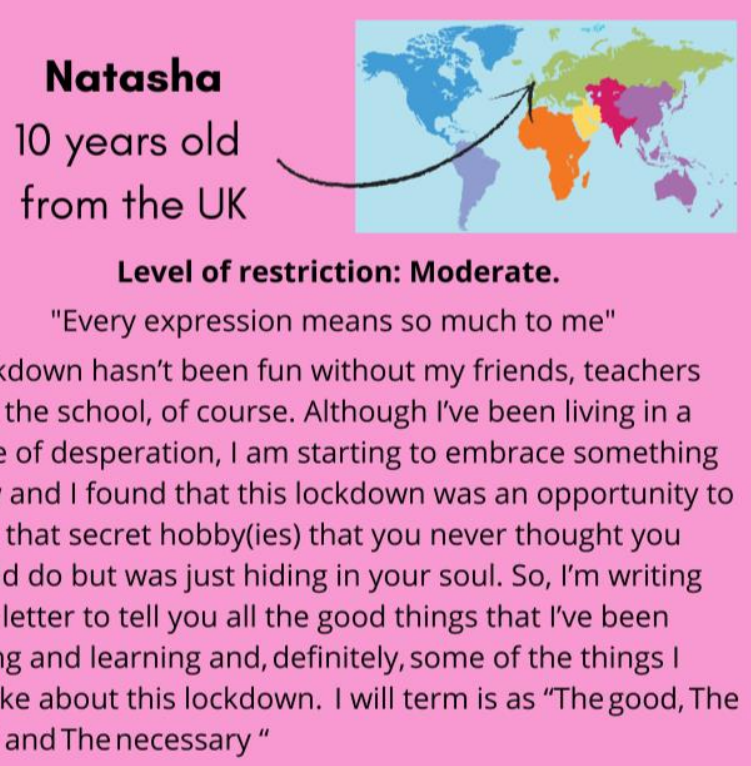

The good!

There is so many things I've learnt during lockdown. It has brought out all these talents and hobbies that, even I, didn't know as I never got the time. Before this pandemic, I used to hate cooking! I never wanted to learn how to cook as I hadn't got time but when Covid-19 came and lockdown commenced, I had plenty of time and decided to dedicate some time to learn how to cook. And now, I know how to make chocolate brownies, rainbow pancakes and scrambled eggs. I also spent time on sewing. Some people say it's for old people, but I think it's a lovely activity that keeps me entertained.

The envelope/purse that I send this letter is what I sewed together myself. I saved the best for last! I made my own app that people can play with. I was so encouraged that my mum got me a robot that I could program and code to do my bidding, even if it was small. She also got me a board called Microbit that I could also code but would show me colours and patterns, but I have to code it.

\section{The bad!}

Ever since myschool close down, life has not been the same because I have no one to play with and I am stuck at home with the same people and things. Whenever I miss my friends, I call them on the iPad using the Facetime app. The most tragic painful part is that I cannot go for parties or attend playdate and sleepover with friends As a result of the lockdown, I sometimes lose track of which day of the week it is. Even though it (has) been quiet all around, I found a way to lighten my day by learning how to make pancakes and other varieties of food. Whenever I did a lot of good accomplishments, I got to buy toys online because all the shops were closed from lockdown. I even bought wardrobe and clothes for my bunny teddy, Daisy (which I got for my 8th birthday). Also because of lockdown, all mysports activities were closed /contd... 
so to keep me occupied therefore I do

my Jado Kuin Do practice at home and exercise using the trampoline,). As my mum is a doctor, a keyworker, her work is prolonged throughout the day, and sometimes, often on Wednesday and Friday, does she go on-call, which is when a keyworker works in the night. Whenever she comes back, I feel sad that, I cannothug her instantly because of the danger of infection from her clothing.

\section{The Necessary!}

1) Whenever I am in the shop, I must stay at least two meters apart from the person in front of me because of social distancing will stop us from spreading any sorts of microorganisms. 2) Any time I sneeze or cough, I have to do it inside my elbows, and if I do it on my hands, I have to wash my hands with soap and water and even better with alcoholic sanitizer. 3) I am not allowed to visit other country or even friends because, to protect us, we do social distancing so we cannot spread it. I hope you thoroughly enjoyed my description of how the lockdown has affected my life.

Yours Sincerely,

Natasha (Kawaii Unicorn), Year 5 Primary School

flexible; there was more time for playing with one's siblings, parents or the household pets: "My family has more time to have fun and hang out together" (Edwin, 11yrs, Sweden). Some children saw being able to sleep in as a positive: "I also used to wake up as early as 05:00 am to get ready for school but now I wake up at 08:00 am since I have nowhere to go" (Jeslyn, 11yrs, Ghana). Other positive experiences included finding the true meaning of love by constantly being together as a family: "I now know the true meaning of love, having been in lockdown with my family" (Layan, 11yrs, Jordan) and in a way "It is a kind of a holiday" (Burak, 10yrs, Turkey).

\section{Positive experiences and emotions: Fun activities}

Fun activities included being able to watch TV: "One good thing about the lockdown is that I get to watch TV more often "(Jerome, 14yrs, Ghana); learn new skills, "I have been learning about art at home school" (Milo, 6yrs, United Kingdom); and doing art projects, "I was playing in the playing ground, I found this broken board. I tried to cut it properly, gathered my acrylic colors and started to paint" (Osama, 10yrs, Jordan). Children said there was more time for fun activities such as swimming, walks which included looking for teddy bears, rainbows, and bike rides: "We go for lots of walks and bike rides and look for bears and rainbows that are in the house windows. One day we spotted 32 bears!" (Eli, 7yrs, Australia). Other positive experiences included cooking "chocolate brownies, rainbow pancakes and scrambled eggs" (Natasha, 10yrs, United Kingdom), sewing, creating apps, playing board and electronic games, on-line purchases and gardening. The artwork below reflects some of these fun activities during COVID-19 (Figures 5 and 6).

Figure 6: Jerome 14 years old from Ghana

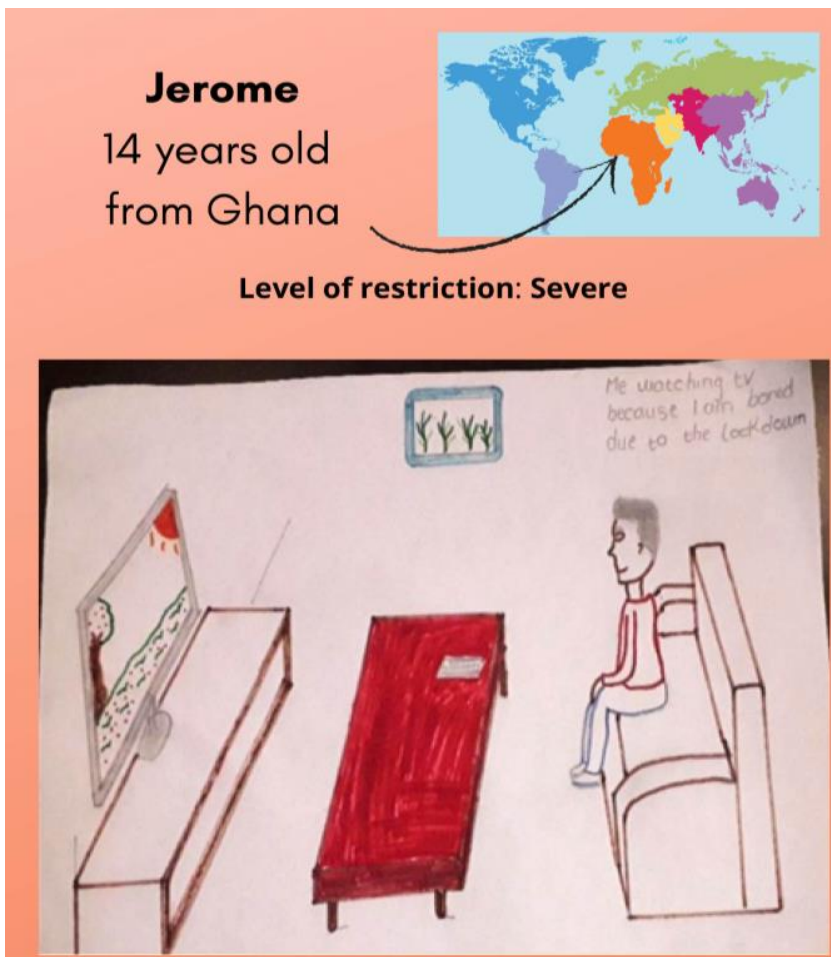

"There are many negative things about the effects of the lockdown caused by Covid-19, but I want to focus on the good things about the lockdown. One good thing about the lockdown is that I get to watch TV more often."

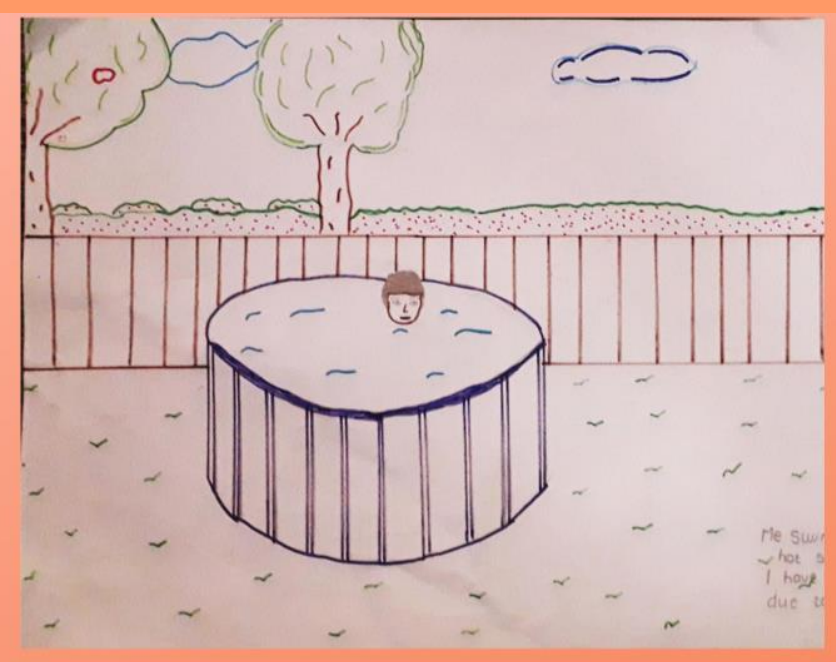

"Another good thing is that since I am always at home, I get to swim more often during the weekdays and not only on weekends especially since I live in a country with very hot temperatures throughout the year." 
Although fun was reported, sometimes a sense of mixed (positive and negative) experiences was evident even within the same art piece with one child explaining "I am not sure if it is something good or bad. It makes me have fun most of the time. But sometimes I feel guilty, it is weird" (Burak, 10yrs, Turkey). Another child also reflected on how good could come out of bad, explaining she felt she was:

living in a cage of desperation.... yet found that this lockdown was an opportunity to find that secret hobby(ies) that you never thought you could do but was just hiding in your soul. [Natasha, 10yrs, United Kingdom]

\section{Negative experiences and emotions}

Negative experiences included the 'social impact' and 'emotional impact' children experienced during the COVID-19 lockdown that were synergistically interconnected.

\section{Negative experiences and emotions: Social impact}

The social impact included children feeling uncomfortable wearing a mask and gloves:

And when we are going out, I have to put on my nose mask and wear my gloves and take my rubbing alcohol. This puts me under a lot of pressure because I feel hot and uncomfortable in the nose mask. [Dromo, 11yrs, Ghana]

Other negative impacts included limited on-line teaching facilities: "We do not go to school and my school is not having any online classes so my dad teaches us at from home" (Djormo, 11yrs, Ghana) and others experienced difficulty in learning at home: "It is very difficult to study on my own without going to school" (Yilmaz, 13yrs, Turkey). No contact with friends or relatives outside of their family bubble was perceived as a negative experience: "We cannot meet with friends and relatives in real because we are not allowed to go out" (Burak, 10yrs, Turkey). Children expressed concern over their grandparent's wellbeing as, "I miss and worry about grandfather and grandmother who are in the risk group" (Axel, 9yrs, Sweden).

Some children stated that they missed their friends, clerical and church events, school, sports, shopping, going to parties or attending playdates or sleep overs:

The corona virus has prevented me from going to school and church. I have missed my friends at church and at my school because there is a ban on social gathering. [Deede, 7yrs, Ghana]

Figure 7: Thabiso 9 years old from South Africa

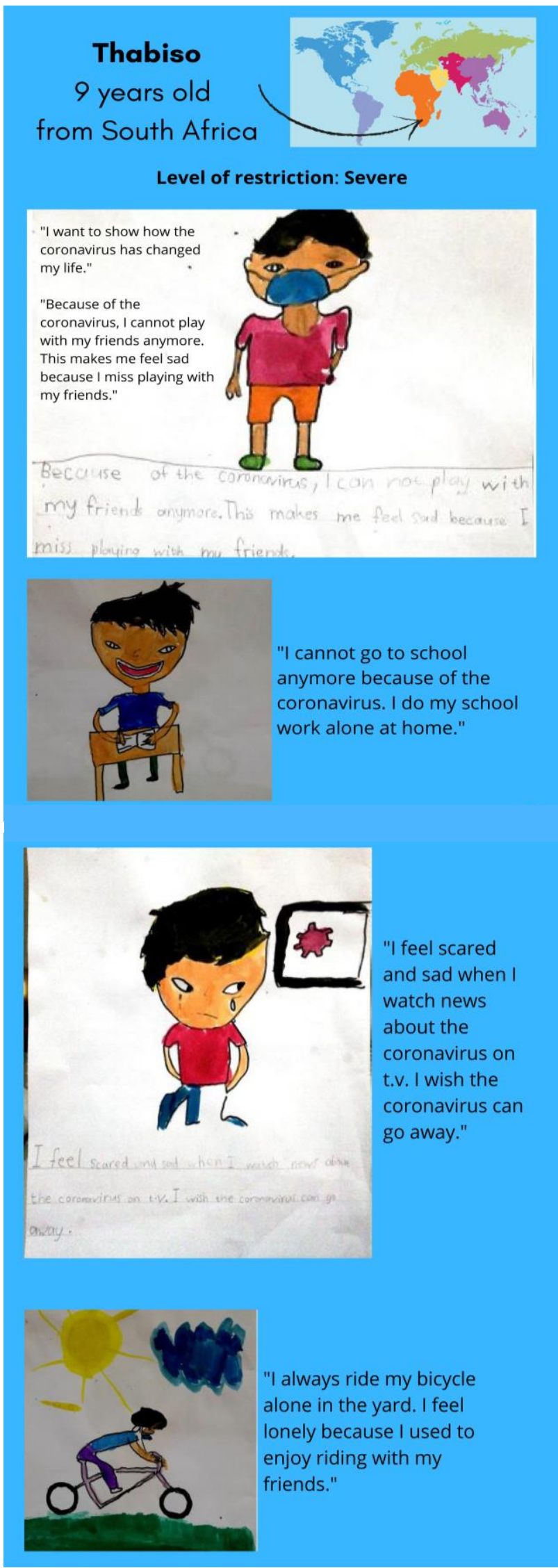


The children wanted to return to normality, noting that "I do not know when all this will be over and when we can live normal lives [that existed] before the pandemic" (Djormo, 11yrs, Ghana). Another child wondered, "When can we really be free, when can we stick our heads out, when will the dawn arrive" (Luyando, 13yrs, Zambia).

The children knew their freedom was restricted by COVID-19 and were clear that they hoped "coronavirus must die!" (Fadi, 9yrs, Australia) or blow away in the wind: "Coronavirus blow away and never come back!” (Pearl, 8yrs, Nigeria). One child drew a dinosaur, and the description was, "The child behind the window is stuck because of COVID. COVID sucks. I wish corona ended and extinct like dinosaurs" (Fadi, 9yrs, Australia).

\section{Negative experiences and emotions: Emotional impact}

The emotional impact included children feeling lonely:

This disease has affected me a lot, because I feel so lonely I cannot go out of the house to play with my friends like I used to. I feel so lonely and miss my friends at school. [TK, 8yrs, Zambia]

Other children expressed that they felt sad because they "cannot play with my friends anymore. This makes me feel sad because I miss playing with my friends" (Thabiso, 9yrs, South Africa). Another child explained:

I choose sad because coronavirus is here, I cannot see my friends in school, it is making people cry and killing people. I want it to go away, so I can be happy and hug again. [Ellise Gold, 6yrs, Nigeria)

Figures 7 and 8 illustrate the emotional impact of COVID-19.

The constant media updates meant that children reported, "I feel scared and sad when I watch news about the coronavirus on TV" (Thabiso, 9yrs, South Africa). The children talked of feeling isolated "feel like I am in a bubble and I cannot interact with the outside world" (Ayzula, 11yrs, America), with "a line between people, which was created by Corona virus" (Jason, 9yrs, America). Children also expressed a sense of a lack of control: "So even when l am at home it feels like I am a prisoner who has been put into jail" (Suomo, 11yrs, Ghana). Some children stated that they missed spontaneous hugs as you always had to wash your hands, and they were bored: "It's been 40 days inside, it's boring."(Odai, 7yrs, Saudi Arabia) and were tired of using electronic devices.

Figure 8: Ayzula 11 years old from USA

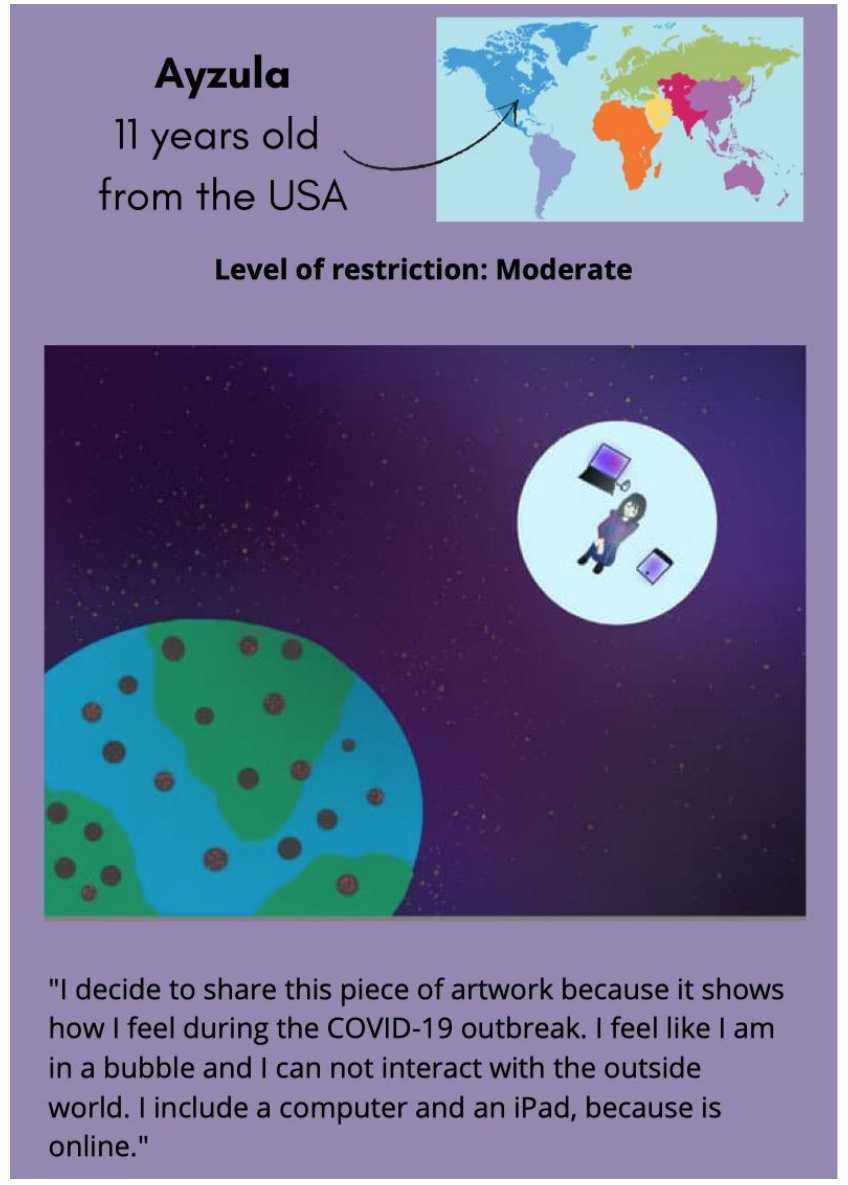

\section{Uniting Children Globally}

Some children wanted to reach out to children in other countries and share their experiences with other children: "I want other children in other countries to know how COVID-19 has affected our life as children" (Glory, 10yrs, Malawi); and "I just want to share my experience and listen to what others also have to say" (Jeslyn, 12yrs, Ghana), as "I don't want other children to be scared of COVID-19 like me" (Annakano, 9yrs, Australia). Sharing their experiences helped to unite them, irrespective of the country they were in, with children warning and supporting each other such as, " COVID19, be careful. One world, one love" (Nin Xuan, 6yrs, Malaysia). Some children relayed special messages in their art pieces for other children, explaining, "But we have to keep smiling and stay safe" (Roisin, 10yrs, Ireland) and, "Most importantly, let's be safe, let's be brave, we shall not fall to this virus" (Luyando, 13yrs, Zambia).

Figures 9 and 10 show how children depicted sharing special messages with each other. 
Figure 9: Hebah 14 years old from Jordan

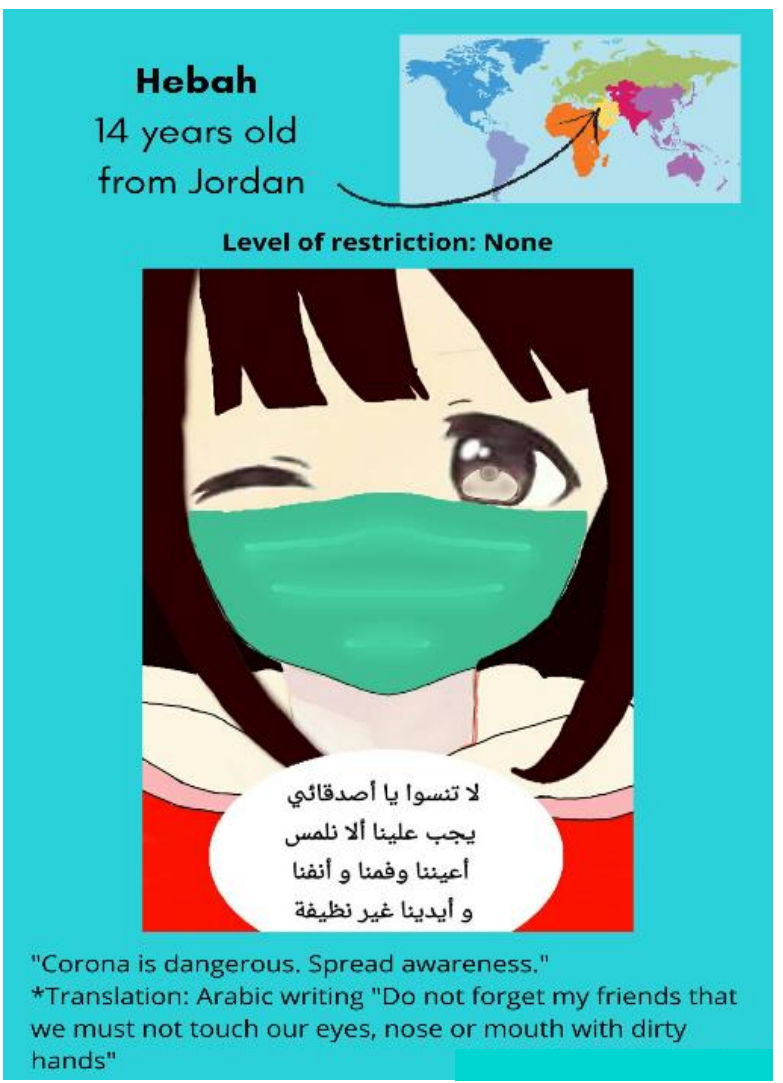

10: Loopa 11 years old from Australia

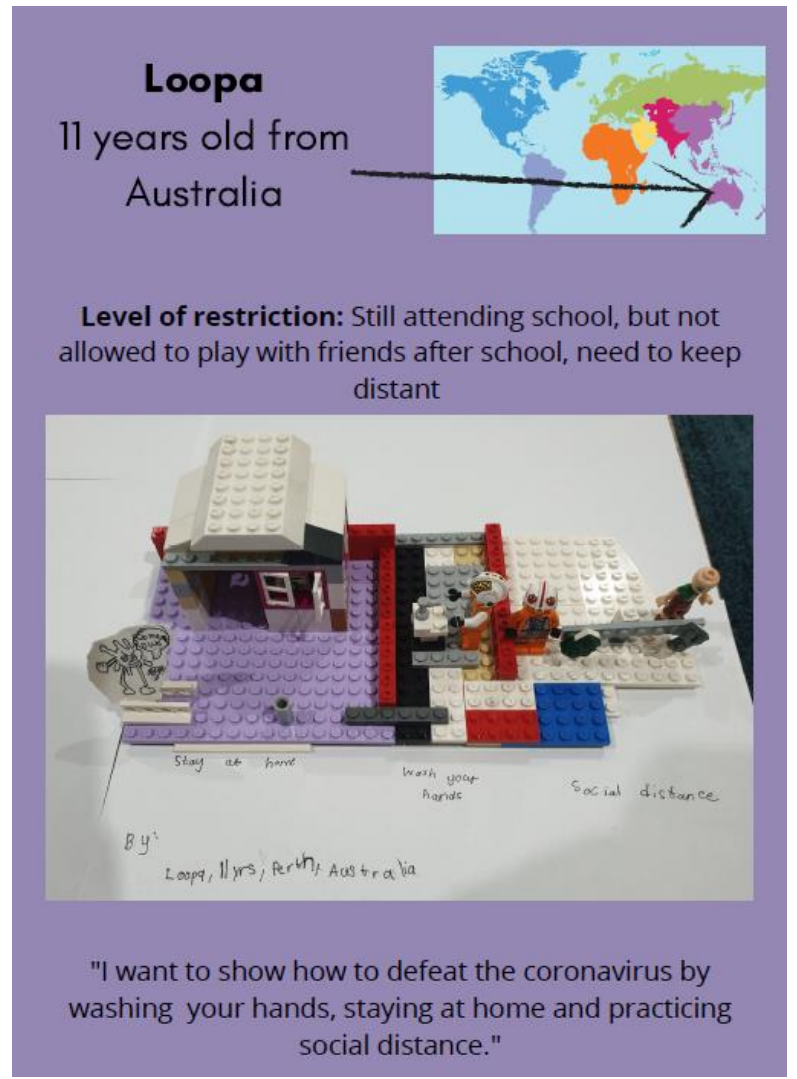

Children also stated that taking part in this project was enjoyable and helpful: "I decided to share my poem because this is how I feel about the virus and I feel better writing about it" (Pearl, 8yrs, Nigeria).

\section{Stage 2: Feelings}

At one of the INCFCC meetings in February 2020, the idea of developing an eBook of children's artwork was discussed as a way to learn from children about their experiences and feelings during the lockdown and that could be shared with other children around the world. It was clear from the artwork the children created and the words, stories and messages they presented, that the eBook helped children to share their feelings and experiences. Although varied in their approach, depth and nature, the children's artwork and written work, demonstrated that most children were reflective and able to give explanations of their art pieces. Reflecting on the work they created made us, in turn, think more deeply about how the pandemic had affected them and we found it quite emotional creating the eBook. It was a project we became more deeply committed to with every child we 'met' through their artwork.

The stories and art from the children aligned with the INCFCC members' feelings of uncertainty and separation from friends and family during the pandemic. It also demonstrated the children's feeling of loneliness related to the restrictions and lockdowns on their inability to go to school, play or travel to see family and friends. Additionally, the uncomfortable feeling of wearing a mask outside was depicted in some of the stories. This experience is like those reported by the adult population (Cheok et al., 2021). In fact, the feelings expressed by children through their artwork show the need for healthcare workers to consider the emotional needs of children during the pandemic and to appreciate that children, like adults, also have feelings that should be acknowledged when providing care.

\section{Stages 3 and 4: Evaluation and Analysis}

This consultative process focused on creative art as a method for understanding children's perspectives on contemporary matters of their lives and the narratives that accompanied their drawings. Children worldwide have shared their lived experiences of COVID-19 restrictions in a unique eBook (INCFCC. 2020b). This COVID-19 Artwork contains drawings, pictures, poems, and narratives from children aged four to 14 years of age, with entries depicting subjects ranging from the difficulties of social distancing to 
"Superheroes against Corona" (Yara, 4yrs, Saudi Arabia).

Reflecting on this process, it is clear that the children were reaching out to other children across the world to share their experiences. What perhaps they did not expect was the profound impact their artwork had on those of us involved in creating the eBook. We were immersed in the creation, layout, editing and dissemination of the eBook and we became close to the children and their art pieces. We came to know about the experiences of children in countries other than our own and it influenced our thinking.

One of the authors of the manuscript (SN) and an editor of the book explained:

"The pandemic has been inescapable, but our young people are living through it in their formative years, so hearing and understanding their perspectives is vital, it is clear from the children's contributions that COVID-19 has impacted on their lives in a big way as well as informing us as professionals we hope that their contributions will help and reassure other children" (King, 2021, para 8).

Although this was meant to provide a venue for children to express their experiences, SN voiced a view within the team that the "child within the authors' adult selves was present by stimulating their own memories of being a child, and the children expressed our exact thoughts."

Another author (BC) and INCFCC member, commented to the group:

It's the international aspect of this book that makes it so special. Everyone has been living through a pandemic and this book unites the children through their experiences - ironically at a time when travel and physical connection are so unlikely; it's a really inspirational piece of work.

Author and co-chair (MA-M) of the INCFCC considered the opportunities this project had given:

Reflecting back to the time when everyone was accommodating to the circumstances brought by this pandemic, this project was one means of saving the moments and capturing the lived experience of children affected by the pandemic. The collective gain from developing the book will be valuable in the understanding and management of future projects. On a personal level, this project provided us with a great opportunity to develop professionally and provide children with the opportunity to express their feelings and convey meaning through the use of creative arts as data collection tools, enabling young children to communicate their experiences and understandings of that experience.

Further to this MF, the originator of the idea who is also affiliated with the International Family Nursing Association, described to the Nursing Times:

This project is incredibly valuable, not just for our network but for anyone worldwide who wants a snapshot of life for children during the pandemic. It's something we're all really proud of, and we're very grateful to the young people involved for sharing their experiences.

(Mitchell, 2021, para 8-9)

On reflecting with the team, MF explained:

This is exactly the same sort of concept in regard to honouring children as valid active capable social agents in society and we need to hear from children about their experiences and what matters to them. We should never assume we know without asking children.

\section{Stage 5: Conclusion}

The team of this project concluded that by using an arts-based on-line approach during the COVID-19 lockdown, children of all ages around the globe were able to participate and provide a variety of art pieces that were meaningful and rich. This project has further enhanced the belief that children of all ages can provide valuable meaningful insightful commentary as capable competent citizens.

This project also brought 21 members of the INCFCC across 12 countries together with regular meetings over 12 months, keeping them connected, engaged and focused on the INCFCC vision. The art eBook is an example of including children to gain a deeper and more meaningful insight into a child's world to direct child focused initiatives, research, legislation, and practice that is underpinned by the United Nations (n.d.) Convention on the Rights of the Child. The 71page Children's COVID-19 Artwork eBook created by children for children (INCFCC, 2020b), is ready for dissemination to children, parents, healthcare professionals, providers, educators, academics, 
researchers, governmental departments, and policy makers globally.

The eBook was publicised by different means in the international media including local radio stations, national and university websites and nursing websites.

\section{Stage 6: Action Plan}

The long-term consequences for children on the COVID-19 pandemic are likely to be far-reaching. The eBook provides some useful insights for professionals working with children and young people across health, social, and education sectors. The Action Plan includes strategies that can be adapted and used to develop and improve practices. Our focus is on four main areas.

Firstly, healthcare and other professionals, including nurses, need to act on the knowledge that children and young people have been impacted by the pandemic. This means that we need to take the hopes, fears, worries, and concerns that they have shared in this project into our everyday encounters with children. The eBook we have produced creates the opportunity for starting a conversation with children by including them in discussions around the impact of COVID-19.

Secondly, there is a need to acknowledge the value of creative arts as a means of facilitating children and young people to express their feelings, experiences and stories.

Thirdly, children and young people make sense of the world around them using information available to them; healthcare professionals need to support their health literacy to enable them to make informed decisions and to feel secure. Examples of ways to support children's independence in the healthcare setting include offering choices where appropriate, having child-friendly videos available to watch in advance and allowing 'warm in' time where children have opportunity to become comfortable in the healthcare setting and ask questions (Nicholl et al., 2020).

Finally, we recommend future research studies exploring children's experiences utilise the medium of creative art to help children express their feelings.

Acknowledgments: The authors wish to acknowledge all members of INCFCC, and all children and their families who participated in creating the book.

\section{References}

Al-Motlaq, M., Carter, B., Neill, S., Hallstrom, I., Foster, M., Coyne, I., Arabiat, D., Darbyshire, P., Feeg, V., \& Shields, L. (2018). Toward developing consensus on familycentred care: An international descriptive study and discussion. Journal of Child Health Care, 23, 458-467. https://doi.org/10.1177/1367493518795341

Al-Motlaq, M., Neill, S., Foster, M., Coyne, I., Houghton, D., Angelhoff, C., Rising-Holmström, M., \& Majamanda, M. (2021). Position statement of the international network for child and family centered care: Child and family centred care during the COVID19 pandemic. Journal of Pediatric Nursing, 61, 140-143. https://doi.org/10.1016/j.pedn.2021.05.002

Al-Motlaq, M., \& Shields, L. (2017). Family-centered care as a Western-centric model in developing countries: Luxury versus necessity. Holistic Nursing Practice, 31, 343-347.

https://doi.org/10.1097/HNP.0000000000000228

Al-Motlaq, M. A. (2021). "There is no corona; it's a conspiracy": Addressing the perceptions of people about COVID-19 through the narrative of their comments on social media. Journal of Consumer Health on the Internet, 25, 65-76.

https://doi.org/10.1080/15398285.2020.1867412

Cheok, G. J. W., Gatot, C., Sim, C. H. S., Ng, Y. H., Tay, K. X. K., Howe, T. S., \& Koh, J. S. B. (2021). Appropriate attitude promotes mask wearing in spite of a significant experience of varying discomfort. Infection, Disease \& Health, 26, 145-151. https://doi.org/10.1016/i.idh.2021.01.002

Cooper, K. (2020). Don't let children be the hidden victims of COVID-19 pandemic. UNICEF.

https://www.unicef.org/press-releases/dont-letchildren-be-hidden-victims-covid-19-pandemic

de Figueiredo, C., Sandre, P., Portugal, L., Mázala-deOliveira, T., da Silva Chagas, L., Raony, Í., Ferreira, E., Giestal-de-Araujo, E., Dos Santos, A., \& Bomfim, P. (2021). COVID-19 pandemic impact on children and adolescents' mental health: Biological, environmental, and social factors. Prog Neuropsychopharmacol Biol Psychiatry, 2.

https://doi.org/10.1016/j.pnpbp.2020.110171

Dewa, L., Crandell, C., Choong, E., Jaques, J., Bottle, A., Kilkenny, C., Lawrence-Jones, A., Di Simplicio, M., Nicholls, D., \& Aylin, P. (2020). CCopeY: A mixedmethods co-produced study on the mental health status and coping strategies of young people during COVID-19 lockdown in the UK. Journal of Adolescent Health, 68, 666-675. https://doi.org/10.1016/j.jadohealth.2021.01.009

Foster, M., \& Shields, L. (2019). Bridging the child and family centred care gap: Therapeutic conversations with children and families. Comprehensive Child and Adolescent Nursing, 1-8. https://doi.org/10.1080/24694193.2018.1559257

Foster, M., Smith, J., \& Neill, S. (2018, 2018/11/01/). Letter to Editor. Journal of Pediatric Nursing, 43, A9. https://doi.org/10.1016/j.pedn.2018.10.019 
Foster, M., \& Whitehead, L. (2018). Using drawings to understand the child's experience of child-centred care on admission to a paediatric high dependency unit. Journal of Child Health Care, 23, 102-117. https://doi.org/10.1177/1367493518778389

Gibbs, G. (1988). Learning by doing: A guide to teaching and learning methods. Further Education Unit. Oxford Polytechnic, UK.

INCFCC. (2020a). The International Network for Child \& Family Centered Care. INCFCC. https://incfcc.weebly.com/

INCFCC. (2020b). Children's COVID-19 Artwork Project. Author. https://incfcc.weebly.com/childrens-artworkproject.html

Jiao, W. Y., Wang, L. N., Liu, J., Fang, S. F., Jiao, F. Y., Pettoello-Mantovani, M., \& Somekh, E. (2020). Behavioral and emotional disorders in children during the COVID-19 epidemic. The Journal of Pediatrics, 221, 264-266. https://doi.org/10.1016/j.jpeds.2020.03.013

King, A. (2021). Unique book contains children's selfpenned experiences of COVID-19 restrictions. University of Plymouth.

https://www.plymouth.ac.uk/news/unique-bookcontains-childrens-self-penned-experiences-of-covid19-restrictions

Lee, J. (2020). Mental health effects of school closures during COVID-19. The Lancet Child \& Adolscent Health, 4, 421. https://doi.org/10.1016/S23524642(20)30109-7

Liu, J., Bao, Y., Huang, X., Shi, J., \& Lu, L. (2020). Mental health considerations for children quarantined because of COVID-19. The Lancet Child \& Adolescent Health, 4, 347-349. https://doi.org/10.1016/S23524642(20)30096-1

Mitchell, G. (2021). Nurse-led book offers 'snapshot' of children's experiences of Covid-19. Nursing Times. https://www.nursingtimes.net/news/children/nurseled-book-offers-snapshot-of-childrens-experiences-ofcovid-19-02-03-2021/

Nearchou, F., Flinn, C., Niland, R., Subramaniam, S., \& Hennessy, E. (2020). Exploring the impact of COVID19 on mental health outcomes in children and adolescents: A systematic review. International Journal of Environmental Research and Public Health, 17(22), article no: 8479. https://doi.org/10.3390/ijerph17228479

Nicholl, A., Evelegh, K., Deering, K., Russell, K., Lawrence, D., Lyons-Wall, P., \& O'Sullivan, T. (2020). Using a respectful approach to child-centred healthcare (ReACH) in a paediatric clinical trial: A feasibility study. PLOS ONE, 15(11), article no: e0241764. https://doi.org/10.1371/journal.pone.0241764

Quaye, A., Coyne, I., Söderbäck, M., \& Hallström, I. (2019). Children's active participation in decision-making processes during hospitalisation: An observational study. Journal of Clinical Nursing, 28, 4523-4537. https://doi.org/10.1111/jocn.15042
Rogers, M. (2018). Listening to children's voices through art: Communicating experiences and understanding in mosaic research. International Art in Early Childhood Research Journal, 1, 1-19.

https://artinearlychildhood.org/journals/2018/ARTE C_2018_Research_Journal_1_Article 5_Roger.pdf

Royal College of Paediatrics and Child Health. (2021). COVID-19 - Research studies on children and young people's views. Author.

https://www.rcpch.ac.uk/resources/covid-19research-studies-children-young-peoples-views

Singh, S., Roy, D., Sinha, K., Parveen, S., Sharma, G., \& Joshi, G. (2020). Impact of COVID-19 and lockdown on mental health of children and adolescents: A narrative review with recommendations. Psychiatry Research, 293, article no: 113429. https://doi.org/10.1016/i.psychres.2020.113429

Smith, J., Shields, L., Neill, S., \& Darbyshire, P. (2017). Losing the child's voice and 'the captive mother': an inevitable legacy of family-centred care? Evidence Based Nursing, 20(3), 67-69. https://doi.org/10.1136/eb-2017-102700

Tang, S., Xiang, M., Cheung, T., \& Xiang, Y. (2021). Mental health and its correlates among children and adolescents during COVID-19 school closure: The importance of parent-child discussion. Journal of Affective Disorders, 279, 353-360. https://doi.org/10.1016/j.jad.2020.10.016

UNICEF. (2020a). COVID 19 and children. Author. https://data.unicef.org/covid-19-and-children/

UNICEF. (2020b). UN News: Global perspective human stories. Author. https://news.un.org/en/tags/unicef

United Nations. (2020). Policy brief: The impact of COVID19 on children. Author.

https://www.un.org/sites/un2.un.org/files/policy bri ef_on_covid_impact on children 16 april 2020.pdf

United Nations. (n.d.). Convention on the rights of the child. Author.

https://www.ohchr.org/en/professionalinterest/page s/crc.aspx

Viner, R. M., Russell, S. J., Croker, H., Packer, J., Ward, J., Stansfield, C., Mytton, O., Bonell, C., \& Booy, R. (2020). School closure and management practices during coronavirus outbreaks including COVID-19: A rapid systematic review. The Lancet Child \& Adolescent Health, 4, 397-404. https://doi.org/10.1016/S23524642(20)30095-X

World Health Organisation. (2020a). MCA and COVID-19: Resources for adolescents and youth. Author. http://www.who.int/maternal child adolescent/links Lcovid-19-mncah-resources-adolescents-andyouth/en/

World Health Organisation. (2020b). WHO Coronavirus (COVID-19) Dashboard. Author. https://covid19.who.int/

\section{Funding: None}

Conflict of interest: None 